control. That warning had already been issued by the great futurist writers of the twentieth century: Orwell, Burgess, Huxley and others. As we emerge from this foreseeable and preventable disaster, we need to remain vigilant. Science is for finding out how the universe works, not for reshaping it into the form we would like it to be.

All predicted events in this account are by definition fictional and any semblance to actual future events will be entirely coincidental.

\section{Howy Jacobs}

EMBO reports (2010) 11, 813-814.

doi:10.1038/embor.2010.165

\section{Our daily bread}

\section{SSS Science \& Society Series on Food and Science}

A bowl of rice, a schnitzel with fries or a 30-course menu-no matter what form it takes, food is the most basic need for humans and a staple of civilization. It is also a major factor in our health and wellbeing; not having enough food causes disease and sickness, as does having too much of it. Malnutrition in impoverished nations is as much of a problem as the epidemic of obesity and associated diseases that are haunting developed and developing countries.

Given the enormous importance of food for humankind, it is puzzling that more money is spent on finding cures for the diseases caused by malnutrition, than on increasing our understanding of the effects of food on our health and how to make better use of such knowledge. Nonetheless, science has taken up the challenge of producing more and better food for a growing human population, and of developing a clearer understanding of the relationship between food and health. It is against this background that $\mathrm{EMBO}$ reports launches a series of articles under the general theme of 'food and science'.

The biological sciences have, of course, much to contribute to the understanding of nutrition and health. Biologists must develop the knowledge to enable the production of sufficient food to sustain a human population that is expected to hit the 9 billion mark by 2050. In addition to raising food production without further degrading the environment, biologists and breeders are also looking at ways to increase the nutritional value of food; the famous 'golden rice' —with an elevated content of vitamin A precursorbeing one of the first examples. Molecular biology research is also needed to improve the analysis and processing of food. Wine making is one area in which plant biology, microbiology, molecular biotechnology and other fields have converged.

Science is also at the forefront of efforts to improve food safety, by tackling chemical and microbial contamination. This remains a global public-health problem that affects all nations, as the recent scandal of Salmonellainfested eggs in the USA demonstrated. Microbiology and biotechnology are important for the development of tools to guarantee that our food remains free from pathogens and toxins.

Science is also unravelling how food influences our health. One particular area that combines the biological and social sciences is the understanding of why humans like and dislike particular foods. This has significant implications for public health; in the light of an epidemic of obesity, a better understanding of the biological and social causes of individual food preferences would help to develop public-health programmes to teach children and their parents how to choose a healthy and balanced diet.

Lastly, the natural sciences-chemistry, biology and physics-have enabled the development of new ways to prepare food, including molecular cooking. Famous chefs such as Ferran Adrià in Spain and Heston Blumenthal in the UK, as well as scientists such as Hervé This and Davide Cassi are revolutionizing cooking. An understanding of food and cooking processes at the molecular level has inspired and informed ingenious ways to prepare and present food.

It is not only biology that analyses our relationship with food; the social sciences are equally important, as our cultural and social environments have a huge influence on what and how we eat. As the series' first article by Jane Wardle and Lucy Cooke (p816) demonstrates, many findings about individual food preferences, including the formative influence of parents and peers, have come from social science and psychology.

Media coverage of food scares and benefits also shapes our preferences. Once again, social science can show how reporting of the latest findings about the health risks and benefits of foods, including broccoli, coffee and chocolate, affects consumer choices in the supermarket or restaurant.

Being able to choose our diet is actually a luxury for a minority. Many humans do not have such a choice; they eat what they can scrape from their land or whatever their limited means can afford. The spike in basic staple prices in 2007/2008 that triggered food shortages and riots in poorer countries is a reminder of how vulnerable millions of people are to the anonymous market forces that dictate global food prices. The economics of food has gained more attention lately: are market prices dictated purely by supply and demand, or are other factors at play? What could be done to temper sudden fluctuations in the future and ensure that markets do not cause hunger and riots again? Will the increasing contribution of science to food production price it beyond the reach of those who need it most?

Agricultural subsidies, particularly in North America and Europe, threaten the livelihoods of millions of poor farmers in developing nations. These subsidies might also have a negative influence on public health in rich nations, by encouraging the production of foods with low nutritional value, such as those with a high carbohydrate content. Economists and nutritionists have begun to look at the links between agricultural policies, food production and consumer preferences.

Science has many challenges to face in food research. It is not only about producing more food, but also producing more nutritious types of food to fight malnutrition. Science is also needed to analyse the link between food and health and to inform public-health programmes. EMBO reports now aims to publish primary research submissions from this and other applied areas of molecular biology.

Ultimately, it will require contributions from all the sciences to achieve these goals. The articles in the 'food and science' series will highlight how the natural and the social sciences are meeting these challenges, in diverse areas. We hope that you will enjoy this menu of articles over the coming months.

\section{Holger Breithaupt}

EMBO reports (2010) 11, 814. doi:10.1038/embor.2010.167 